\title{
Centro de informação jurídica eletrônico e virtual
}

\author{
Ana Paula de Rezende \\ Graduada pela Escola de Biblioteconomia/UFMG em 1995, \\ Bibliotecária responsável pelo Centro de Informação, \\ Documentação e Biblioteca do escritório jurídico JN\&C \\ Advocacia Associada S/C. \\ E-mail: jnc@gold.com.br
}

\section{INTRODUÇÃO}

Até pouco tempo, para se obter informação jurisprudencial ou ainda doutrinária sobre determinadas questões de Direito, o advogado ou pesquisador recorria a ultrapassados bancos de dados (ultrapassados, porque até que fossem publicadas determinadas decisões, como o Direito está em constante mutação, haveria outras que com certeza, poderiam sobrepor-se às primeiras).

Hoje, além da mídia, contamos com avançados meios eletrônicos e virtuais que possibilitam obter a informação em poucos segundos. A jurisprudência pode ser conseguida na íntegra em pouco tempo e logo aproveitada ou descartada de acordo com o caso.

Todos os profissionais interessados em conseguir tais informações devem se preocupar em não apenas conhecer, mas principalmente saber explorar essas novas tecnologias para que aproveitem ao máximo, sem sentirem-nas como estorvos em seus trabalhos.

Repassamos nossas experiências em relação às modificações ocorridas na JNC Advocacia, que poderá servir de modelo aos demais escritórios, e as etapas da implantação do Centro de Informações Jurídicas que hoje não se admite sem os meios eletrônicos e virtuais, o qual chamamos de Centro de Informação Jurídica Eletrônico e Virtual (Cijev). Partindo da biblioteca jurídica tradicional existente, aproveitamos seus recursos físicos, materiais e humanos e adquirimos, com cautela, tecnologia de ponta, que será usada para o resgate de informação na conexão de bancos de dados em redes.

\section{BIBLIOTECAS VIRTUAIS EM ESCRITÓRIOS JURÍDICOS}

Nos dias atuais, o volume de informações geradas e consumidas vêm aumentando aceleradamente, e estas deixam seu suporte físico tradicional para tornarem-se digitais. Neste novo contexto, a tecnologia da informação pode ser considerada uma das principais ferramentas a serem utilizadas para obtenção de ganhos de qualidade e produtividade, principalmente se considerarmos sua rapidez e confiabilidade. Hoje, as empresas têm investido muito mais em pesquisas, com vistas a criar sistemas de

Artigo aceito para publicação em 29/03/2000 
informação que atendam às suas necessidades específicas, permitindo o acesso ao máximo de informações relevantes ao decisor.

"Não basta, portanto, ter disponíveis as informações, em alguns casos isto pode até dificultar ainda mais os resultados. É preciso que as informações disponibilizadas estejam organizadas e acessíveis a tempo de vencer os prazos e a concorrência.” (Rezende, 1998)

Destaca-se, dentro deste quadro, o conceito de "biblioteca virtual", que está relacionado com o conceito de acesso por meio de redes a recursos informacionais disponíveis em sistemas de base computadorizada, criando a oportunidade de melhoria da qualidade dos serviços e produtos da biblioteca que devem visar à eficiência, à qualidade, ao serviço orientado ao usuário e ao retorno de investimento, mesmo que de forma indireta, otimizando a prestação de serviços da empresa em questão.

Para Wolthers (1998), o segredo está em recuperar a informação, e não guardá-la. "O desafio é criar sistemas de consultas que levem o usuário ao documento procurado", complementa.

Para os usuários, esta nova biblioteca é uma perspectiva de aumentar a rapidez ao acesso aos materiais, selecionando-os da imensidão de documentos disponíveis, eliminar ainda as visitas físicas em excesso à biblioteca, utilizando a biblioteca de suas próprias mesas, onde os materiais estarão sempre disponíveis.

Como os bibliotecários e profissionais da área de informática, também o advogado sentiu a necessidade de acompanhar a evolução da disponibilização da informação jurídica.

Rezende fala ainda sobre o envolvimento de vários fatores nos escritórios de advocacia:

"Nos escritórios de advocacia, vistos como indústrias que processam e transferem conhecimento, na busca de soluções para os problemas do cliente, a essência do trabalho é a manipulação, reelaboração e transferência de informações. $\mathrm{O}$ conhecimento acumulado e transferido no ambiente de um escritório de advocacia envolve tecnologia, conteúdo informacional e, principalmente, interação entre pessoas.” (Rezende, 1998)

Esta mudança, coloca em discussão o papel de bibliotecários e bibliotecas tradicionais, que, para sobreviver, devem se adaptar e também participar ativamente de novos processos de gerenciamento da informação.
Concomitante, a informação só será significativa, se vier acompanhada de "...oportunidade, exatidão e relevância". (Davenport, 1958,p.151) Aqui a importância entre se trabalhar a informação, e não apenas carregar bases informatizadas com dados primários.

Logo, concluímos que pessoas são ainda os melhores "meios" de identificar, filtrar, interpretar e integrar informações.

Assim, o bibliotecário deverá ser, aqui, mais um provedor de informações, do que um especialista em aquisição ou catalogação. Entre as novas funções que irá exercer, estão as seguintes:

- gerenciar a busca e acesso a fontes de informação relevantes aos serviços da empresa de advocacia, onde quer que elas se encontrem, pois esta localização de endereços eletrônicos relevantes, entre os milhões cadastrados na rede não é nada fácil, por não haver listas semelhantes às telefônicas, e a criação, extinção e mudança destes endereços ocorrem com uma velocidade extraordinária;

- antecipar a interação entre fontes e usuários;

- estudar aspectos comerciais, legais, culturais e profissionais de acesso a estas informações;

- estabelecer parcerias com fornecedores e autores, verificando a procedência, seleção, disponibilização e confiabilidade da informação que irá prover aos seus usuários;

- personalizar a informação, analisando e sintetizando-a, de forma a permitir que esta chegue ao usuário refinada e condensada, de acordo com o perfil deste (Disseminação Seletiva da Informação - DSI);

- manter listagens de novos sites e bases disponíveis em rede para manter os usuários atualizados com relação à biblioteca virtual.

Com base na verificação da necessidade de acompanhar a evolução das tecnologias de disponibilização da informação e documentação jurídica*, o Centro de Informação Jurídica Eletrônica e Virtual (Cijev) propõe a inserção destas novas tecnologias no CIDB/JNEC Advocacia, buscando otimizar os serviços prestados por este. Assim, o CIDB tornar-seá um membro mais ativo na estrutura da instituição, por

\footnotetext{
*Entende-se por documentação jurídica "a reunião, análise e indexação da doutrina, da legislação, da jurisprudência e de todos os documentos oficiais relativos a atos normativos ou administrativos". (Atienza, 1979)
} 
meio da criação desta rede de distribuição interna que adicionará valor às demandas, respondendo às necessidades informacionais dos advogados.

Com a necessidade de colocar a informação ao alcance dos advogados, quando e onde for necessário e, por outro lado, com o aumento do volume de publicações na área do Direito, além das constantes mudanças na legislação brasileira, torna-se difícil, sem a ajuda da informática, gerenciar, disseminar e recuperar toda esta informação em tempo hábil. A informática representa fator fundamental no processo de recuperação da informação, e a cada momento surgem novas tecnologias que permitem uma interação direta entre usuários e sistemas. Daí a necessidade em se implantar tecnologia de ponta na gerência da informação no Cijev.

Em A empresa na velocidade do pensamento, Bill Gates sugere que as empresas criem um sistema nervoso digital que permita um fluxo rápido e eficiente de informações, alegando que somente estas sobreviverão, e aborda algumas questões essenciais para que isso aconteça, revelando como um sistema nervoso digital pode, por exemplo:

- ajudar a empresa a reagir mais rapidamente a problemas e oportunidades;

- converter todo processo que envolva papel em um processo digital, economizando tempo dos funcionários para outras atividades;

- abrigar equipes virtuais interdepartamentais visando ao intercâmbio de idéias e experiências;

- manter os funcionários em contato constante entre si e com os sistemas de informação da empresa, estimulandoos a desenvolver e aplicar estratégias empresariais, contribuindo para o crescimento da mesma.

Com o objetivo de recuperar a informação de forma rápida e eficiente, os mais diversos centros de informação e bibliotecas vêm utilizando alguns recursos, como a construção de bases de dados, que são fontes de informação automatizada e que podem ser pesquisadas de diversos modos.

A comodidade em se possuir informação sempre em mão faz com que o advogado possa argumentar com mais eficácia nas decisões a serem tomadas. Outro recurso tecnológico utilizado é o CD-ROM, disco compacto de memória apenas para leitura, que suporta as mais criativas bases de dados em multimídia e tem muitas vantagens, como a grande capacidade de armazenamento, podendo conter milhões de páginas de texto, permitindo o uso de sons e imagens gráficas de fácil utilização. $O$ que se deve observar é que a aquisição destes CD's deve ser feita de forma criteriosa, observando-se fontes seguras e recursos que realmente facilitam a busca.

Hoje, nos tribunais superiores, já existe uma grande utilização desta tecnologia para armazenar e disponibilizar o acesso aos bancos de dados de interesse público, mas, no que concerne à armazenagem definitiva (substituição do papel), ainda estão sendo realizados estudos acerca deste suporte (tempo de duração e possíveis problemas). Rezende (1998) cita: “... o fato de que nos últimos dois anos os tribunais vêm disponibilizando seus julgados através da Internet e também de discos óticos...”. E acrescenta, citando Atheniense (1996), "inobstante à média do espaço imobiliário ocupado pelos escritórios de advocacia ter diminuído bastante recentemente, dificultando a guarda de coleções numerosas de jurisprudência e legislação, o mercado de informática recepcionou no último biênio a entrada marcante de antigos livreiros no mercado de informática, através de lançamentos de legislação, jurisprudência e códigos comentados em CD. ROM.".

A Internet é atualmente a palavra de ordem como fonte de informação. Disponibilizando os seus mais diversos serviços, possibilita o acesso a uma enorme quantidade de bases de dados e também aos acervos de várias instituições e bibliotecas, de maneira rápida e eficiente.

Nela, o pesquisador encontrará milhões de possibilidades, porém, se não for orientado, perderá informações relevantes ao seu trabalho. Além da ligação com todas as fontes de informação jurídica, o usuário da Internet ainda tem a chance de discutir com grupos de interesses comuns suas idéias.

Por isso, o trabalho de seleção deve ser criterioso, a busca por sites que realmente vão lhe valer, além da disponibilização de mais que uma alternativa para cada tipo de pesquisa (lembrando que a Internet é uma rede online que pode não estar disponível no momento preciso).

Indiscutivelmente, um canal de informação e comunicação até então incomparável. No entanto, alguns detalhes devem ser observados para que esta não se torne, ao invés de um facilitador, seu antônimo. Por exemplo, a velocidade do equipamento que a vincula, o provedor e a disponibilização de uma linha telefônica somente para pesquisas são detalhes que não podem ser esquecidos. 


\section{A EMPRESA JN\&C ADVOCACIA ASSOCIADA S/C}

A JN\&C Advocacia Associada S/C é uma entidade civil, prestadora de serviços técnico-profissionais de advocacia especializada em direito municipal, administrativo e constitucional.

Presta serviços de patrocínio judicial e extrajudicial de causas, serviços de consultoria, assessoria e assistência jurídica a prefeitos, prefeituras, câmaras municipais e outras entidades públicas, estudos jurídicos de implantação de reforma administrativa de prefeituras e câmaras municipais e emissão de pareceres jurídicos em matéria de direito público, notadamente de direito municipal.

Possui uma equipe de profissionais especializados, sob a coordenação, orientação e supervisão do professor doutor José Nilo de Castro. Esta equipe é formada por advogados e estagiários de Direito, além da bibliotecária e dos assistentes, tendo como clientes municípios mineiros, além de alguns de outros estados.

Salientamos que a JN\&Cé uma empresa que preza o estudo profundo do Direito municipal. Deste ponto vimos a paixão por este, quando, além de doutorado e todos os títulos que possui, o professor José Nilo de Castro, autor de várias obras, investe no conhecimento e o passa, incentivando a criação. Como exemplo disso temos a criação recente do Instituto de Direito Municipal (IDM), com o objetivo de estudar e difundir o Direito municipal, apoiando e orientando as diversas entidades e pessoas interessadas; a criação da JN\&C Eventos Jurídicos, promovendo ciclos de estudos; com a aquisição e equipação de um auditório, denominado M. Seabra Fagundes; com a edição da Revista de Direito Municipal JNËC, proporcionando a seus funcionários atualização constante e oportunidade da convivência íntima com este ramo do Direito, além dos cursos e congressos em que estão sempre presentes.

\section{CENTRO DE INFORMAÇÃO, DOCUMENTAÇÃO E BIBLIOTECA (CIDB)}

A empresa conta com um setor de pesquisa denominado Centro de Informação, Documentação e Biblioteca $\mathrm{CIDB} / \mathrm{JN} \& \mathrm{C}$ Advocacia.

O CIDB/JN\&C conta com os serviços especializados de uma bibliotecária e uma digitadora, além de uma estagiária de biblioteconomia. Seu acervo é especializado em Direito, com ênfase em Direito público, não deixando de possuir material básico da coleção de referência e algumas obras de interesse geral.

Sendo mais de $90 \%$ impresso em papel, o idioma predominante é o português, $25 \%$ do acervo estão em outras línguas, predominando primeiramente o francês, seguido do espanhol, depois do inglês, além do italiano e alemão. É composto por livros, anais, periódicos, jornais, jurisprudência - recortes e acórdãos, documentos de clientes - e documentos em outros suportes, além do papel: fitas de vídeo, fitas de audio, CD's, fotografias, portifólio do diretor, portifólio da JN\&C.

Serviços oferecidos:

- pesquisa internas e externas (doutrina, jurisprudência, legislação, produções documentais e documentos referentes aos processos de clientes);

- boletim informativo mensal;

- lista de aquisições mensais;

- atualização com novas aquisições;

- pesquisa de assuntos para os ciclos de estudos da JNC Eventos e IDM;

- integração com o grupo de discussão da informação jurídica de Minas Gerais e utilização de seu catálogo de bibliotecas públicas ou privadas especializadas em direito.

O CIDB/JN\&C possui uma base de dados capaz de recuperar a menor informação física que esta possua, em tempo hábil e eficaz. Isto se deve ao trabalho de informatização da biblioteca*, que foi realizado depois de estudos com afinco por pessoal especializado**, vencendo, assim, a primeira etapa da implantação do Cijev.

Sua proposta vai além do serviço especializado ao seu usuário direto, mas à promoção da empresa; ao enriquecimento de seu acervo; à satisfação do cliente; à divulgação de seus trabalhos e à promoção da cultura e do conhecimento.

Com a necessidade da existência do Cijev, o planejamento é fundamental, principalmente, porque deve-se conhecer o ambiente externo e interno da empresa, posicionando-se perante as oportunidades e ameaças ambientais. Assim,

* Quando citamos "Biblioteca" estamos nos referindo a toda parte de informação organizada e processada no escritório, inclusive documentos de clientes.

** Bibliotecária, analista de sistemas e advogado. 
serão obtidos dados relevantes às próximas etapas da implantação do Centro de Informações Jurídicas Eletrônico e Virtual, considerando que este implicará aquisição de tecnologia de ponta.

Para esta primeira etapa, foram observados dados importantes como os que seguem abaixo:

\section{Missão}

Disseminar informações precisas e prestar correta assistência à empresa para que esta inicie, mantenha e conclua suas atividades, entendendo e participando do processo de evolução e manutenção dos níveis de competitividade e lucratividade da empresa.

\section{Ambiente interno e externo}

Em tempos de recessão, a empresa tem se mostrado resistente às tempestades econômicas e sociais. Atualmente, passou por grandes modificações, como o aumento considerável de número de funcionários, aumento de contratos, as mudanças na estrutura organizacional e a inserção de tecnologia de ponta em todos os setores, entre eles o CIDB.

\section{Público}

É constituído por um conjunto de instituições e grupos formais e informais que influenciam, possuem interesses e contribuem ou podem contribuir de maneira positiva ou negativa para o seu desempenho.

O CIDB conta com fornecedores de serviços e equipamentos de informática, de material de escritório, editoras e livrarias, bem como recursos que prestam apoio no atendimento de consultas como bases de dados e fóruns eletrônicos, instituições da área jurídica, universidades, institutos de pesquisa, serviços e unidades de informação afins. Seus usuários são os advogados e estagiários da empresa, prefeitos, prefeituras, câmaras e empresas com as quais o CIDB mantém intercâmbio, além de faculdades e instituições de direito administrativo por se tratar do doutor Nilo participante e atuante advogado desta área.

Os usuários, devido à maior demanda de trabalho, necessitam de respostas mais rápidas e ágeis, o que implica necessidade de otimização dos serviços, seja no nível administrativo ou operacional. Assim, surge a necessidade de se inserir toda e qualquer informação relevante em bases de dados on-line, com vistas a descentralizar as pesquisas e tornar os usuários mais independentes.

\section{A IMPLANTAÇÃO DO CIJEV}

Alguns passos para implantação do Centro de Informação Jurídica, Eletrônica e Virtual, primeiramente, foi criada uma comissão composta pela bibliotecária, um advogado (mais assíduo ao CIDB) e o técnico responsável pela informática, que fizeram o seguinte:

- analisaram, orçaram e adquiriram equipamentos de informática compatíveis com as necessidades deste empreendimento, bem como softwares;

- também, identificaram as áreas da coleção impressa, para desta forma definir quais assuntos devem ser adquiridos em meio eletrônico;

- identificaram, orçaram e adquiriram CD's jurídicos relevantes à pesquisa e desenvolvimento de trabalhos jurídicos;

- verificaram as leis de propriedade intelectual de documentos eletrônicos;

- identificaram condições para o acesso a redes, outras bibliotecas e bases de dados;

- identificaram e selecionaram sites jurídicos e outros relevantes;

- reformularam a política de desenvolvimento de coleções da empresa;

- reorganizaram o fluxo de trabalho do CIDB, disponibilizando recursos humanos para as funções dirigidas tecnologicamente;

- conscientizaram os usuários no que concerne ao novo conceito de acesso à informação em rede, através de cursos e palestras;

- promoveram cursos para os recursos humanos deslocados para esta função;

- controlaram o vocabulário jurídico utilizado para indexação no escritório.

Ao longo de nosso trabalho, analisamos também os pontos fracos e fortes da biblioteca em relação a implantação do Cijev.

Durante a análise destes pontos, pode-se destacar um ponto fraco, que na realidade é vivenciado pela maioria dos escritórios: 
- mudança constante de tecnologia, o que às vezes gera morosidade e adaptações;

e muitos pontos positivos:

- riqueza de recursos informacionais;

- acompanhamento e emprego de novas tecnologias;

- integração com outras entidades privadas e públicas da área jurídica;

- alta freqüência dos usuários;

- a automatização do acervo, o que agiliza as pesquisas e a disponibilização da informação gerada pelo CIDB;

- o treinamento de usuários, que é considerado imprescindível e acontece com freqüência;

- novo leiaute, que atende melhor às necessidades do CIDB e a seus usuários (com mais espaço para a centralização da documentação).

Os recursos existentes no CIDB vêm atendendo às necessidades práticas dos usuários. Porém, a necessidade de alocação de maiores recursos, a busca de novas oportunidades de inovação de produtos e serviços e também a pressão externa (usuários) sofrida pelo CIDB obrigam a uma atitude de antecipação às demandas e necessidades dos advogados, com o objetivo de proporcionar a estes, em tempo hábil, respostas relevantes à tomada de decisão.

Também temos de levar em conta que algumas funções referentes à informação dos usuários, no que concerne à tomada de decisão (produto final), não podem perder-se nos setores que auxiliam essas atividades.

Por isso, sugerimos que cada pesquisador, seja ele advogado, estagiário, o próprio bibliotecário ou ainda um auxiliar, tenha acesso a todas as possibilidades de pesquisa em um ambiente próprio (que já existe), de forma sistematizada, organizada e simplificada, refletindo boa imagem da empresa para o cliente (que normalmente não entende os processos internos desta).

\section{TECNOLOGIA}

Pittman \& Kelly (1990) apontam como vantagens de um sistema computadorizado e que podem ser ressaltadas na utilização de um sistema especialista:

“1) confiabilidade dos dados; 2) acessibilidade dos dados; 3) organização em um modelo estrutural; 4) flexibilidade para usar múltiplos meios de acesso; 5) segurança para garantir a confidencialidade; 6) interpretação dos dados e análises; 7) compatibilidade e padronização dos dados; 8) suporte a decisão em tomadas de decisão rotinizadas".

São três os recursos tecnológicos que, depois do planejamento estratégico, sistematizarão o Cijev: automação do acervo interno, a utilização da internet e a aquisição e uso de cd's.

\section{Automação - escolha do software}

A automação tem como principal objetivo colocar ao alcance do usuário uma base de dados com informações internas de documentos e materiais bibliográficos gerados ou adquiridos pela empresa, de forma a facilitar seu acesso.

Primeiramente, foi feito um estudo das necessidades reais do usuário e suas expectativas em relação à automação. Neste, foi detectada a necessidade de automação do material bibliográfico da empresa e para facilitar e agilizar a busca por doutrina, jurisprudência e legislação. Também detectou-se a necessidade do uso de um software para controle de processos de clientes. Depois dos estudos com usuários, foi definido o projeto de automação, que, segundo Kryzanowski (1996), possui alguns procedimentos básicos. Veja-se:

- "analisar profundamente a situação atual, a flexibilidade e a capacidade de processamento;

- definir os requisitos básicos e atividades que irão atender as necessidades do sistema;

- verificar se o software escolhido possui backup, analisar seu desempenho (tempo de processamento), se permite importação e exportação de dados, avaliar seu custo/ benefício se é compatível com o orçamento disponível;

- não se esquecer de observar a instalação elétrica e a temperatura ambiente deste;

- certificar-se se possui padrões de conexão com redes locais externas; 
- levantar os possíveis problemas físicos que podem surgir para impedir a instalação e utilização do software e hardware;

- procurar verificar antecipadamente como será o contrato com o fornecedor e a sua manutenção;"

Além dos citados, ainda acrescentamos, em relação a escolha de softwares, os critérios abaixo:

- levantar diversos softwares nacionais e internacionais da área que possam atender às expectativas, verificando os itens anteriormente citados. Se ainda assim não convier, considerar a possibilidade de desenvolvimento de software personalizado;

- procurar saber quais são os clientes do fornecedor do software - se esiverem satisfeitos, se preciso, fazer uma visita técnica;

- se necessário, analisar a possibilidade de obtenção de recursos externos para realização do projeto.

Ainda assim, o projeto deve ser acompanhado por um grupo de profissionais para todas as etapas, no mínimo pelos citados no quadro de recursos humanos deste trabalho. O cronograma deve ser acompanhado em todos os seus detalhes, inclusive deve-se fazer uma média de quantos dados serão inseridos por hora/dia/mês.

Para automação do acervo, deve-se traçar um plano, que deve responder às questões:

- Quem vai atender? Quem vai pesquisar?

- Quais as principais necessidades? O que se espera?

- Haverá impressão de relatórios?

- Qual tipo de material fará parte da coleção automatizada?

Alguns detalhes devem ser observados, como a contratação de um digitador, o preenchimento de planilhas e a correta indexação dos documentos de acordo com um vocabulário jurídico de termos que devem ser sempre consultados. Também devem ser definidas questões como o uso de símbolos, de acentos, como devem entrar, por exemplo: legislações.

O CIDB/JN\&C utiliza como software para automação do seu acervo bibliográfico o MICROISIS, desenvolvido pela Unesco, utilizado em várias bibliotecas no Brasil e em outros países, com grande capacidade de armazenamento e principalmente com grande facilidade de se recuperar todos os dados inseridos, motivo que pesou na escolha do mesmo. Foi desenvolvido por um profissional de informática que, junto com a bibliotecária, definiu os campos para alimentação de dados e pesquisas.

Para o acompanhamento processual, depois de várias análises (pois neste campo o mercado é bem vasto), existem muitos outros de igual natureza e sua escolha depende dos critérios já oportunamente citados. Escolheuse um que, segundo os estudos e demonstrações, atenderá bem aos advogados no que concerne seu principal objetivo, que é manter o cliente informado do andamento de seus processos. Entre suas funções, está permitir a organização de dados, o controle da rotina diária e a integração das atividades de um escritório jurídico, por meio de módulos que oferecem uma série de recursos. Aproveitamos para identificar cada documento de acordo com a tabela de classificação adotada no arquivo da empresa, tornando a busca destes ainda mais acessível.

Há grande importância em se treinar o pessoal, tanto o que vai alimentar, quanto o usuário definitivo do sistema. Um treinamento sólido e metódico corresponde a uma base de dados bem utilizada.

\section{Internet - seleção de sites}

Aqui, a agilidade de respostas se dá mediante a seleção de sites jurídicos na Internet, criando uma listagem de favoritos na área do Direito administrativo, especialmente Direito municipal, além de outros como tribunais, órgãos governamentais, bibliotecas jurídicas, universidades, periódicos jurídicos, grupos de discussão na área etc.

$\mathrm{Na}$ imensidão de sites jurídicos, encontramos tribunais, escritórios, órgãos governamentais, e não editoras, jornais, ou seja, uma gama de serviços e comércios que disponibilizam, em suas páginas, informações para todas as necessidades.

A seleção deve ser abrangente. Primeiramente, deve-se fazer um levantamento de todos os órgãos da justiça que geralmente são consultados (seja por causa das decisões destes ou ainda por indicações.

Pode-se optar pelos caminhos de busca (catálogos), sugestões, endereços em jornais jurídicos, revistas e ainda aproveitar cada site visitado para verificar sua lista de sugestão de links que deve ser consultada e analisada, selecionando, assim, mais algum para sua listagem, gravando-os em um bookmaster ou lista de favoritos. 
O ideal é a busca de informações, no órgão de origem destas, para depois, hierarquicamente, em outros sites.

Sua lista, poderá ficar assim organizada:

Favoritos:

$$
\begin{aligned}
& \text { Advocacia } \\
& \text { Legislação } \\
& \text { Jornais } \\
& \text { Revistas } \\
& \text { Editoras } \\
& \text { Escritórios } \\
& \text { Tribunais } \\
& \text { Outros órgãos }
\end{aligned}
$$

A partir daí, há ilimitadas possibilidades de pesquisa à sua disposição. Por exemplo, para colecionar decisões, formando um banco de dados, pode-se fazê-lo virtualmente. Selecionam-se as decisões de interesse e gravam-se em uma pasta em seu computador, dando-lhe um nome, depois classificam-se os documentos para que sejam recuperados. Para não acumulá-los na memória, você pode gravar em discos e tê-los sempre por perto.

\section{A seleção e aquisição de CD's - recursos multimídia}

Nossa meta aqui é implantar um sistema de gerenciamento da informação em suporte CD de legislação, jurisprudência e outros, que permita consulta, em rede, às informações contidas neste.

Colocando ao alcance do usuário, com rapidez e objetividade, todos os atos dos poderes Executivo, Legislativo e Judiciário, bem como dos órgãos da administração direta e indireta, quer federais, estaduais ou municipais. Estas são as principais ferramentas do trabalho destes, e o maior e mais rápido acesso a estas informações otimizará o atendimento e conseqüentemente a satisfação do cliente.

Antes de qualquer passo para selecionar ou adquirir CD's, devemos conhecer as fontes de informação legislativa e quais os fornecedores desta área, fazendo então um paralelo entre o que precisaremos e onde encontraremos. Veja-se:

\section{Fontes de Informação Legislativa}

A necessidade pela busca da informação hoje é freqüente, e o universo desta é muito maior.
Hoje a aplicação do conhecimento torna-se fundamental para o bom desempenho de todas as atividades do cidadão, principalmente pela administração pública (licitações e contratos, servidores e todos os atos desta).

Para facilitar esta busca, devemos entender primeiro o processo legislativo e sua abrangência.

As normas jurídicas se dividem em superiores e marginálias e podem ser federais, estaduais e municipais.

As normas superiores são geradas a partir de uma norma maior de ação, abrangem mais pessoas de forma geral. E são elas: leis, leis complementares, medidas provisórias, decretos.

Já as normas inferiores são geradas por órgãos para determinados grupos de pessoas ou áreas. $\mathrm{O}$ controle e acesso são mais difíceis. Existem em grande volume porque são muito minuciosas e pela quantidade de órgãos que existem. Muitas vezes, não são publicadas, dificultando ainda mais o seu acesso.

Outra questão é a da informação legislativa em construção - muitas vezes já se pode construir uma relação entre os três níveis, e a pesquisa neste tipo de legislação é muito difícil.

Devem-se listar os tipos de fontes de informação, seu suporte e onde provavelmente você vai encontrá-la. Como, por exemplo:

- Base de dados, Prodabel;

- Jornais Oficiais, D.O.U, D.O.M. e outros;

- Coletâneas, CD-Rom/Prodabel;

- Livros e periódicos, Boletins.

Devemos observar que várias questões devem ser analisadas, a questão de espaço físico para guarda de publicações, equipamentos, operacionais, de disponibilização, usuários (muitas vezes, este é resistente, precisando de informação impressa).

Os custos dos CD's e equipamentos compatíveis, das horas da Internet, o problema de atualização.

As empresas fornecedoras (fontes) devem ser confiáveis, deve-se saber quais são seus clientes, quais são seus recursos de impressão, pesquisa, visualização e abrangência. 


\section{RECURSOS UTILIZADOS PARA IMPLEMENTAÇÃO}

Precisamos utilizar alguns recursos humanos e materiais que devem também ser descriminados detalhadamente, inclusive com valores a serem gastos, para que se possa verificar a viabilidade do projeto. Os recursos citados a seguir foram levantados de acordo com o que já possuíamos na JN\&C Advocacia e de acordo com o que o mercado oferece em termos de novidades tecnológicas na época do levantamento (término 1998):

\begin{tabular}{lccc}
\hline Profissional & Quantidade & Situação & Valor *. \\
\hline Advogado & 01 & Já existe & - \\
Bibliotecário & 01 & Já existe & - \\
Digitador & 01 & Contratado & $-\mathrm{R} \$ 500,00$ \\
Técnico em & & & mensais \\
informática & 01 & Já existe & - \\
\hline
\end{tabular}

Material/Equipamento

\begin{tabular}{lclc}
\hline Tipo & Quantidade & Situação & Valor $^{*}$ \\
\hline Pentium 400 MHZ - & 01 & Já existe & - \\
$64 \mathrm{MB}-\mathrm{HD} 8.0 \mathrm{~GB}$ & & & \\
Multimídia $40 \mathrm{x}$ & 01 & Já existe & - \\
Torre CD's & & Adquirir & $\mathrm{R} \$ 2000,00$ \\
P/10 unidades & & & \\
CD's & Vê relação & Já existe & - \\
Servidor & 01 & Já existe & - \\
Placa de Moden mais & 01 & Adquirir & $-\mathrm{R} \$ 300,00$ \\
avançado para Internet & & & \\
Linha Telefônica para & 01 & Transferir & - \\
Internet & & & \\
\hline
\end{tabular}

* Valores estimados apenas para demonstração

\section{DISPONIBILIZAÇÃO DO CENTRO DE INFORMAÇÃO JURÍDICA ELETRÔNICA E VIRTUAL (CIJEV) AOS USUÁRIOS}

Como já dissemos no início do trabalho, a tecnologia da informação vem sofrendo transformações constantes. Por isso, não devemos nos esquecer que o Cijev deve estar sempre atualizado de acordo com as novas tecnologias, programas, novos sites e em harmonia com a política de seleção, aquisição e descarte do CIDB/JN\&C. Esta política objetiva definir os suportes do acervo da biblioteca, procurar manter o desenvolvimento do acervo dentro de um alto padrão de eficácia de acordo com a demanda, promover o crescimento racional e equilibrado do acervo dentro dos critérios estabelecidos, propiciar um bom aproveitamento dos recursos financeiros disponíveis, bem como a questão do espaço físico, acondicionamento, utilização e outros, além de determinar os critérios e prioridades para aquisição e descarte de material bibliográfico.

O Cijev é gerenciado pelo Centro de Informação, Documentação e Biblioteca (CIDB), da JN\&C Advocacia. Funciona na empresa com acesso em rede.

Hoje, nossos usuários podem utilizar-se da disponibilidade de acesso a:

- base de dados utilizada para controle de material bibliográfico;

- base de dados utilizada para acompanhamento processual de clientes;

- base de dados utilizada para verificação de processos junto aos tribunais e fórum;

- Internet - disponível para pesquisa local (rede mundial de pesquisa);

- futuramente, Catálogo coletivo GDIJ/MG - disponível para pesquisa local (catálogo coletivo de publicações periódicas assinadas por cada membro do Grupo de Discussão e Informação Jurídica está em processamento);

$-\mathrm{CD}$ 's;

- legislação federal/códigos;

- ementa de jurisprudência em diversos tribunais/ doutrinas;

- enciclopédia/dicionário geral.*

\footnotetext{
* Sugestão para aquisição.
} 


\section{CONCLUSÃO}

Concluímos que foi fundamental o estudo e um acompanhamento sistemático de todo o processo de implantação e funcionamento do Cijev. Além disto, todo o trabalho deve estar voltado para atender também ao processo de gestão de coleções bibliográficas, a disseminação da informação, aos trabalhos cooperativos, compartilhamento de recursos computacionais, ao acompanhamento da área jurídica seja nacional ou internacional, principalmente no que diz respeito à especificidade em que o escritório atua.

Levando-se em conta o custo/benefício do Cijev, pode-se dizer que este pôde ser implantado com tranqüilidade no $\mathrm{CIDB} / \mathrm{JN} \& \mathrm{C}$, que já dispunha de alguns recursos materiais, de pessoal capacitado e, além disso, porque todo o processo de automação do acervo foi iniciado antes da sua implantação, facilitando a pesquisa das informações que já se possuía, seguindo-se, depois, todas as etapas descritas.

Percebemos a importância do bibliotecário que trabalha na área jurídica, devendo este ser ágil e cumprir seu novo papel: de provedor da informação, principalmente, no que concerne às peculiaridades desta área.

É evidente que um processo de mudança e transformação de um setor traz transtornos, principalmente, quando tem que se trabalhar com todo o acervo, item por item. Um exemplo concreto disso são as páginas da Web quando estão em criação ou transformação, com toda a sua lentidão natural do processo devido à dificuldade de acesso. Mas este deve ser contornado e compreendido pelos usuários, pois, após este processo, os benefícios serão consideráveis.

O Centro de Informação Jurídica Eletrônico e Virtual (Cijev) vem modernizar e completar a estrutura de pesquisa do Centro de Informação, Documentação e Biblioteca (CIDB) da JN\&C Advocacia Associada, oferecendo condições suficientes ao bom atendimento a seus clientes no fornecimento de produtos com qualidade, tornando-a, juntamente com toda a qualificação de sua equipe e de seu diretor, uma empresa bem preparada em relação às exigências de competitividade para o novo milênio.

\section{Agradecimentos}

Agradeço a toda equipe JN\&C e principalmente ao doutor José Nilo pela credibilidade e confiança depositados em minha pessoa para a realização de meu trabalho neste escritório. Também agradeço à estagiária de biblioteconomia Valéria Maria Machado por sua ajuda inicial, que muito me incentivou.

\section{REFERÊNCIAS BIBLIOGRÁFICAS}

1. ATHENIENSE < Alexandre. Advocacia e Informática: redefinindo conceitos na advocacia atual no final do século. Boletim Jurídico Travelnet [on line] 5p. <http:www.travelnet.com.br/jurídica/art31 a 96.htm $>$ [1996, out 18].

2. ATIENZA, Cecília Andreotti. Documentação jurídica: introdução à análise e indexação de atos legais. Rio de Janeiro, Achiamé, 1979. 266p.

3. CASTRO, Luiz Fernando Martins. A internet como meio de distribuição da informação. In: I CIBERÉTICA - Simpósio Internacional de Propriedade Intelectual, Informação e Ética. Florianópolis, SC Brasil 19 a 21 de novembro de 1998.

4. DAVENPORT, Thomas H. PRUSAK, Laurence. Ecologia da Informação. São Paulo, Futura, 1998. 316p.

5. GATTES, Bill. As empresas na velocidade do pensamento. São Paulo, Companhia das Letras, 1999.448p.

6. GUIMARÃES, José Augusto Chaves. Formas da Informação jurídica: um contribuição para a sua abordagem temática. Revista Brasileira de Biblioteconomia e Documentação, São Paulo, V. 26, n.1/2, p.4154. Jan./jun. 1993

7. KRAEMER, Lígia Leindorf. MARCHIORI, Patrícia Zeni. Automação documentária: contribuições conceituais para a prática. [ on line] $\leq$ www.unb.br/fa/cid/rbb/artigo2.htm >

8. KRIZANOWISKI, Rosaly Favero. Subsídios para análise, seleção e aquisição do software para gerenciamento de biblioteca: experiência do Sistema Integrado de Bibliotecas da USP(SIBi/SP). São Paulo: SIBi/ USP, 1996.

9. MARTINS FILHO, Plínio. Direitos autorais na internet. Ciência da Informação, V.27, N.2, P.183-188, mai/ago,1998.

10. MARQUES JÚNIOR, Alaôr Messias. Fontes de Informação Jurídico - legislativas. Perspectivas em Ciência da Informação, Belo Horizonte, EBUFMG, v.2,n.2,p.163-174, jul/dez.1997.

11. OHIRA, Maria de Lourdes Blatt. OLIVEIRA, Sueli Ferreira Júlio de. Utilização de tecnologias de Informação pelas bibliotecas da área jurídica de Florianópolis, SC. Revista ACB: Biblioteconomia em Santa Catarina, Florianópolis, V. 2, n.2, p.77-93. 1997

12. PITTMAN, Sharon A. KELLY, Michael J. ILRA: a Knowledge based system link to na electronic resource file. Information and Referral, v. 12, n.1-2, p. 16-27, Summer Winter, 1990.

13. REZENDE, Martha Izabel de Souza Duarte. Gerenciamento da informação e do conhecimento no escritório de advocacia.In...I CIBERÉTICA. Simpósio Internacional de Propriedade Intelectual, Informação e Ética. Florianópolis, SC, 19 a 21 de novembro de 1998

14. SALVATO. Gilberto José. Aplicabilidade de sistema especialista em serviços de referência de Bibliotecas Especializadas. In: I CIBERÁTICA - Simpósio Internacional de Propriedade Intelectual, Informação e Ética. Florianópolis, SC - Brasil 19 a 21 novembro de 1998.

15. STUBER, Walter D.. FRANCO, Ana Cristina. Internet sob a ótica jurídica: Um estudo sobre os aspectos jurídicos na rede.[On line] In: <http:\\cf3.uol.com.br.8000/consultor/ arti.cfm? numero $=667>$ 